Eur. J. Clin. Chem. Clin. Biochem.

Vol. 29, 1991, pp. 783-786

(C) 1991 Walter de Gruyter \& Co.

Berlin - New York

\title{
Infradian Rhythms of Alanine Aminopeptidase Excretion During Gentamicin Therapy
}

\author{
By D. Balschun ${ }^{1}, U$. Burchardt ${ }^{2}, M$. Klagge $^{2}$ and W. Stein ${ }^{2}$ \\ ${ }^{1}$ Institut für Neurobiologie und Hirnforschung, Magdeburg \\ ${ }^{2}$ Klinikum Frankfurt (Oder)
}

(Received March 28/October 17, 1991)

\begin{abstract}
Summary: Urinary excretion of alanine aminopeptidase (EC 3.4.11.2) was examined in 30 patients (22 women, 8 men, range 38-81 years; mean age 55.4) receiving gentamicin in a therapeutic dosage, which was based on the monitored blood creatinine concentration. In general, therapy lasted 10 days. The excretion of 24 individuals displayed significant infradian rhythms with periods between 2.2 and 8.1 days. In 10 of these 24 patients $(42 \%)$ a circaseptan period was detected. The high portion of circaseptan rhythms might have been induced by the detrimental effects of gentamicin on the proximal tubule and the resulting processes of reconstitution.
\end{abstract}

\section{Introduction}

Measurements of enzyme activities in urine provide sensitive diagnostic indicators for the early detection of renal diseases $(1,2)$. They are used as a valuable tool for the recognition and assessment of nephrotoxic side effects of drugs (3). To enhance the diagnostic validity of urinary enzyme measurements all factors influencing enzyme activity in vivo and in vitro must be minimized or standardized. Among the endogenous factors which have to be considered biological rhythms of various frequencies play an important role.

Apart from the well-known circadian changes in enzymuria (see 1.c. $(3,4)$ ) little is .known of excretion rhythms with longer periods. Grötsch et al. (6) reported infradian rhythms between 7 and 9 days in the rat. In previous investigations on healthy volunteers (7) we demonstrated that in man the excretion of tubular enzymes is subject to marked infradian changes with a mean period of about 10 to 14 days. The aim of the present study was to clarify whether the infradian rhythmicity is influenced by the nephrotoxic aminoglycoside, gentamicin, frequently used to combat Gram-negative infections.

\section{Materials and Methods}

Thirty patients ( 22 women, 8 men, range $38-81$ years; mean age 55.4) suffering from pyelonephritis received gentamicin in a therapeutic dosage according to the monitored blood creatinine concentration. In general, therapy lasted 10 days. No attempts were made to standardize influences such as waking and sleeping periods and fluid intake, which are known to affect the timing of body functions. The purpose was to study the infradian enzyme output under clinical routine conditions.

For enzyme determinations the morning urine was collected and prepared as previously described (7).

Alanine aminopeptidase ${ }^{1}$ ) activity was determined using the artificial chromogenic substrate alanine-4-nitroanilide (final concentration in the reaction mixture $2 \mathrm{mmol} / \mathrm{l}$ in $50 \mu \mathrm{mol}$ Tris, pH 7.8). Creatinine was assessed by a kinetic method.

Relevant periodicities in the time series were detected in three subsequent steps:

1. The general increase in enzyme excretion caused by the gentamicin treatment was fitted by a fifth degree polynomial. The calculated polynomial was subtracted from the original data.

The fifth degree polynomial could be shown to provide a good fit to the short-time series used here. Non-linear regression of such a polynomial is fast and easy to handle with respect to

\footnotetext{
1) Enzyme

Alanine aminopeptidase (EC 3.4.11.2)
} 
the selection of suitable initial values. However, if a longer time series including the drug-induced rise as well as a longer time span of baseline levels has to be fitted, the application of the following function is recommended:

$$
y=a \times x^{b} \times e^{-c \times x^{d}}
$$

The use of this function requires a careful selection of the initial values to ensure convergence of the non-linear fit.

2. Dominant periods in the remaining data were detected by the maximum entropy method (MEM) using computer algorithms taken from l.c. (8).

The maximum entropy method (all-poles model, autoregressive model) belongs to modelling approaches to spectral estimation. These methods characterize a signal (time series) by a model. The model parameters are determined by solving a set of linear equations and are subsequently used to estimate the power spectrum of the signal. Maximum entropy methods suggest that the estimated autocorrelation function should be predicted beyond the data-limited range. The principle of this extrapolation is that the spectral estimate must be the most random, i. e. must have the maximum entropy.
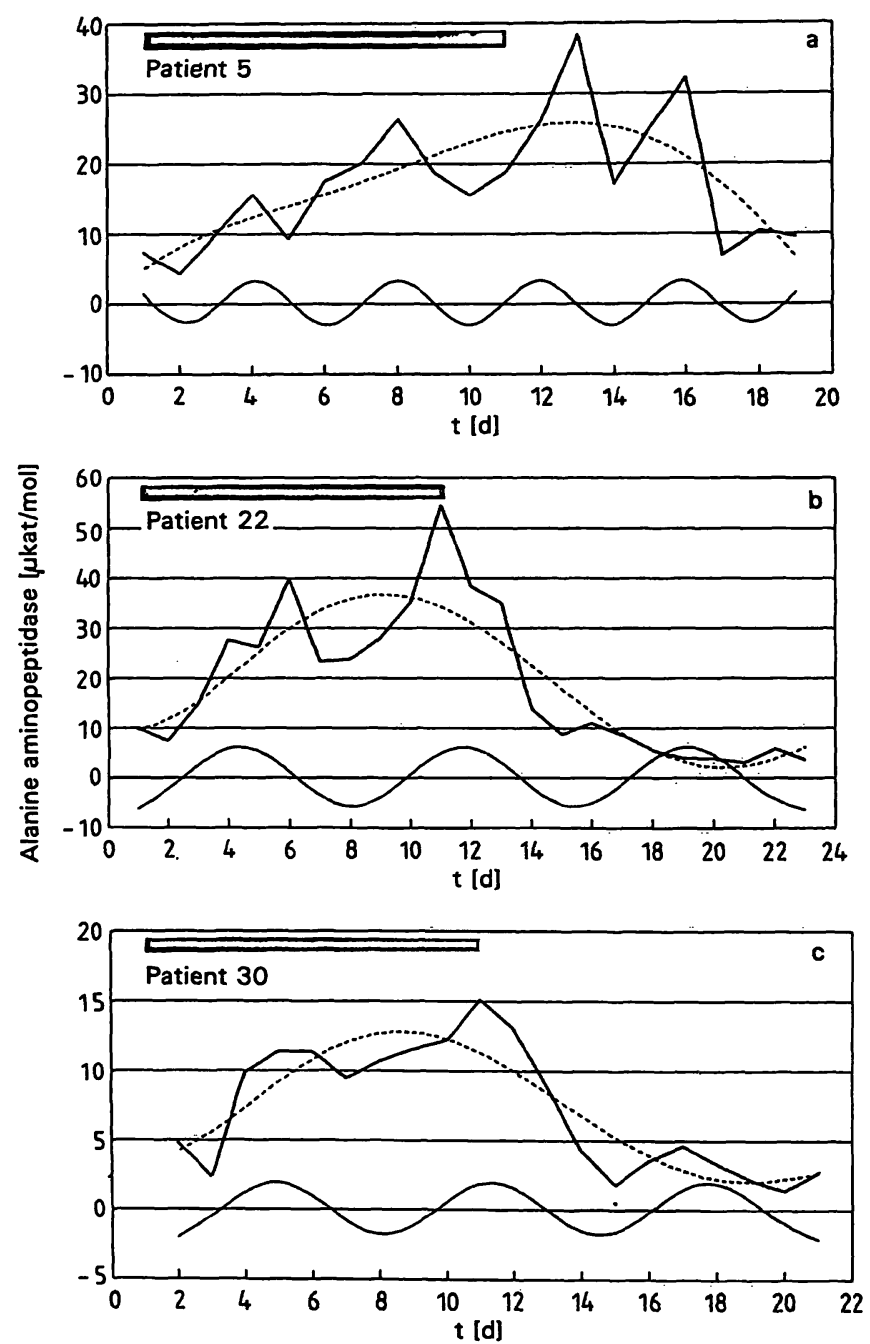

Fig. 1. Excretion patterns of alanine aminopeptidase in three patients treated with therapeutic doses of gentamicin. The alanine aminopeptidase activity was calculated per mol urinary creatinine. The horizontal black bar indicates the gentamicin treatment. The trend (dotted line) was approximated by a fifth degree polynomial. The thin continuous line represents the best fitting cosine function after removal of this trend.
Maximum entropy method has the property of producing high resolution spectra even for short data sequences. For a detailed description of the method see 1.c. (9). Information on practical application and comparison of maximum entropy method with Fourier transform methods is to be found in 1.c. (10).

3. The results of maximum entropy method were used as initial values for a cosine fit to the data. The results consisted of estimates of period $(T)$, amplitude ( $(\dot{A})$, mesor $(M)$ and phase (Ф) of the best fitting cosine functions, and the respective $95 \%$ confidence intervals.

\section{Results}

The experimental data agree well with the often reported finding of an increase in enzymuria under gentamicin treatment (e.g. (3)). As an example the temporal course of the alanine aminopeptidase excretion of three patients is depicted in figure 1 . The influence of this general rise on the time series analysis was eliminated by fitting a fifth degree polynomial to the original data. This function was subtracted subsequently. The remaining data were computed with maximum entropy method and non-linear regression.

In most cases the maximum entropy method spectra before and after the subtraction of the polynomial agreed well, implying that the chosen procedure was suitable. Figure 2 shows the maximum entropy
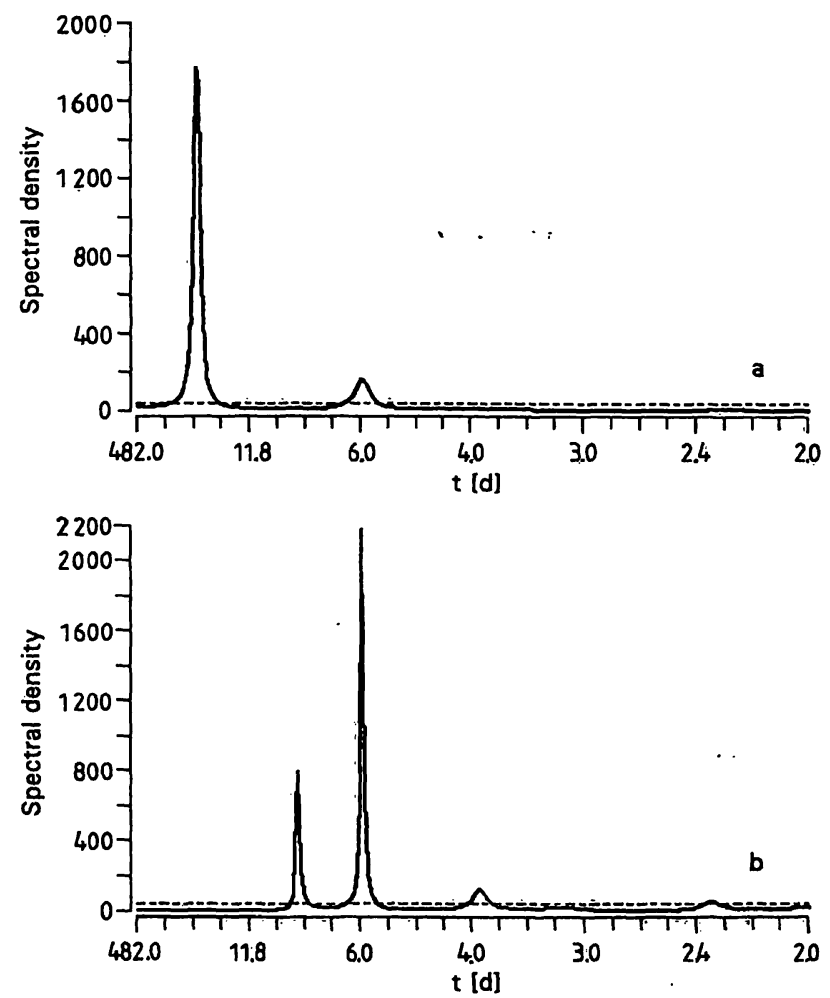

Fig. 2. Power spectra of the alanine aminopeptidase excretion pattern of patient 30 estimated by the maximum entropy method (MEM).

a: Spectrum of the original time series.

b: Spectrum after removal of the trend in the baseline level (dotted line in fig. 1) caused by the gentamicin treatment. 
method spectra of patient 30 . As can be seen in figure $2 a$ the spectrum of the original data is dominated by the gentamicin-induced baseline alteration. Therefore, this non-rhythmic influence overrides the rhythmic components. After removing this trend the dominant rhythmic components can be estimated by maximum entropy method (fig. $2 b$ ) and a subsequent non-linear fitting of cosine functions.

As already described by us for healthy volunteers (7), the data of the 30 patients showed a high individuality. As depicted in table 1, infradian periods between 2.2 and 8.1 days were revealed. In the case of six subjects no significant fitting was possible. Ten of the remaining 24 patients $(42 \%)$ displayed significant circaseptan (7 \pm 1 days) rhythms. The detected rhythms exhibited amplitudes up to $65 \%$ with a mean of $29 \%$.

\section{Discussion}

Rhythms in enzymuria cover at least a range from 24 hours $(4,5)$ to 44 days (7). Even longer rhythms seem to occur, since Grötsch et al. (11) reported seasonal differences in the excretion of alanine aminopeptidase and four other enzymes in rats under constant lightdark conditions. In the majority of our data, more than one significant period was detected, indicating that periodicity in enzymuria represents a complex phenomenon, possibly regulated by different internal pacemakers.

Not only enzyme excretion but also the concentration of aminoglycosides have been found to undergo infradian changes. Gilbert et al. (12) observed a cycling renal concentration of gentamicin in rats. Each cycle covered a period of about 17 days, but the sampling

Tab. 1. Results of non-linear regressions after removing the trend approximated by a fifth degree polynomial.

Mesor ( $\mu \mathrm{kat} / \mathrm{mol}$ creatinine), amplitude ( $\mu \mathrm{kat} / \mathrm{mol}$ creatinine), period (days), phase (days) and the respective $95 \%$ confidence intervals of the best-fitting cosine functions are given. n. s. = no significance of cosine fit

\begin{tabular}{|c|c|c|c|c|c|c|}
\hline No & Sex & Period & & Amplitude & Mesor & Phase \\
\hline 1 & 0 & $3.67 \pm 0.40$ & & $0.86 \pm 0.66$ & $-0.01 \pm 0.47$ & $0.12 \pm 1.70$ \\
\hline 1 & $d$ & $5.64 \pm 0.96$ & & $0.83 \pm 0.69$ & $-0.10 \pm 0.49$ & $2.62 \pm 1.70$ \\
\hline 2 & $\sigma$ & $7.55 \pm 0.92$ & & $1.93 \pm 1.25$ & $-0.05 \pm 0.90$ & $3.34 \pm 1.28$ \\
\hline 3 & $\delta$ & $2.23 \pm 0.08$ & & $5.92 \pm 4.60$ & $0.13 \pm 3.15$ & $1.00 \pm 1.47$ \\
\hline 4 & $\delta$ & $6.08 \pm 0.80$ & & $1.98 \pm 1.45$ & $0.14 \pm 1.02$ & $4.47 \pm 1.61$ \\
\hline 5 & $\sigma$ & $3.92 \pm 0.35$ & & $4.76 \pm 3.97$ & $0.15 \pm 2.79$ & $3.62 \pm 1.63$ \\
\hline 6 & 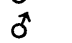 & $5.28 \pm 0.37$ & & $46.02 \pm 31.72$ & $-0.01 \pm 22.14$ & $0.63 \pm 1.35$ \\
\hline 7 & $\sigma$ & $4.25 \pm 0.67$ & & $0.28 \pm 0.20$ & $-0.03 \pm 0.13$ & $3.25 \pm 1.28$ \\
\hline 8 & 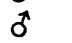 & $5.18 \pm 0.39$ & & $10.15 \pm 8.14$ & $-0.44 \pm 5.53$ & $2.50 \pm 1.49$ \\
\hline 9 & q & n.s. & & & & \\
\hline 10 & o & $2.27 \pm 0.11$ & & $2.50 \pm 2.30$ & $-0.05 \pm 1.54$ & $3.06 \pm 1.67$ \\
\hline 10 & o & $6.67 \pm 0.80$ & & $3.07 \pm 1.93$ & $0.00 \pm 1.40$ & $6.45 \pm 1.30$ \\
\hline 11 & q & $6.54 \pm 1.09$ & & $0.80 \pm 0.45$ & $0.10 \pm 0.33$ & $7.97 \pm 2.90$ \\
\hline 12 & q & $5.18 \pm 0.58$ & & $1.67 \pm 1.42$ & $-0.05 \pm 1.00$ & $2.14 \pm 1.71$ \\
\hline 13 & ㅇ & n.s. & & & & \\
\hline 14 & q & $6.60 \pm 1.59$ & & $4.09 \pm 2.54$ & $0.07 \pm 1.87$ & $4.48 \pm 1.55$ \\
\hline 15 & 우 & $4.97 \pm 0.51$ & & $3.40 \pm 2.82$ & $0.10 \pm 2.02$ & $1.00 \pm 1.81$ \\
\hline 15 & iq & $7.35 \pm 0.95$ & & $3.62 \pm 2.88$ & $-0.01 \pm 1.99$ & $5.00 \pm 1.53$ \\
\hline 16 & $\dot{q}$ & n. s. & & & & \\
\hline 17 & .9 & $2.32 \pm 0.10$ & & $5.50 \pm 2.74$ & $-0.05 \pm 1.74$ & $-4.08 \pm 0.87$ \\
\hline 18 & o & n.s. & & & & \\
\hline 19 & 우 & n.s. & & & & \\
\hline 20 & o & $3.20 \pm 0.34$ & & $0.59 \pm 0.48$ & $-0.03 \pm 0.33$ & $0.66 \pm 1.74$ \\
\hline 21 & ㅇ & $2.20 \pm 0.05$ & - & $0.73 \pm 0.38$ & $0.00 \pm 0.28$ & $2.12 \pm 0.96$ \\
\hline 21 & 우 & $8.13 \pm 0.66$ & & $2.21 \pm 0.98$ & $-0.12 \pm 0.70$ & $4.33 \pm 0.85$ \\
\hline 22 & q & $7.39 \pm 0.80$ & & $6.65 \pm 3.64$ & $0.23 \pm 2.69$ & $2.59 \pm 1.22$ \\
\hline 23 & iq & $5.44 \pm 0.47$ & & $1.74 \pm 1.25$ & $0.04 \pm 0.88$ & $5.91 \pm 1.41$ \\
\hline 24 & o & $4.66 \pm 0.64$ & & $1.33 \pm 0.96$ & $0.15 \pm 0.65$ & $4.63 \pm 1.23$ \\
\hline 25 & q & $2.60 \pm 0.30$ & & $1.94 \pm 1.38$ & $-0.42 \pm 1.00$ & $-1.58 \pm 5.02$ \\
\hline 25 & 우 & $6.68 \pm 1.07$ & & $2.81 \pm 1.37$ & $0.02 \pm 0.99$ & $2.11 \pm 1.13$ \\
\hline 26 & o & $5.05 \pm 0.93$ & & $0.11 \pm 0.10$ & $0.02 \pm 0.06$ & $4.95 \pm 1.79$ \\
\hline 27 & 우 & $5.31 \pm 0.37$ & & $3.74 \pm 2.23$ & $0.13 \pm 1.45$ & $2.27 \pm 1.04$ \\
\hline 27 & 우 & $8.06 \pm 1.34$ & & $2.76 \pm 2.66$ & $-0.21 \pm 1.73$ & $4.50 \pm 1.60$ \\
\hline 28 & 웅 & $6.53 \pm 0.42$ & & $4.72 \pm 1.88$ & $0.19 \pm 1.33$ & $6.37 \pm 0.87$ \\
\hline 29 & q & n.s. & & & & \\
\hline 30 & 우 & $6.43 \pm 0.55$ & & $2.16 \pm 0.94$ & $0.07 \pm 0.70$ & $1.50 \pm 1.05$ \\
\hline
\end{tabular}


interval was relatively long, so that shorter periods could have been masked.

Under normal conditions the circaseptan range does not seem to be of paramount importance. However, the application of the nephrotoxic aminoglycoside, gentamicin, led to an amplification of circaseptan periods. Gentamicin causes more or less pronounced alterations in the brush border membrane of proximal tubules, the segment where alanine aminopeptidase represents one of the dominant proteases. The proximal tubule is particularly vulnerable because $75 \%$ of the filtered water and high amounts of other substances are re-absorbed here. Due to the resulting metabolic strain the proximal tubule is very sensitive to nephrotoxic agents (13).

\section{References}

1. Burchardt, U., Peters, J. E., Neef, L., Thulin, H., Gründig, C. A. \& Haschen, R. J. (1977) Der diagnostische Wert von Enzymbestimmungen im Harn. Z. Med. Labor-Diagn. 18, $190-212$.

2. Price, R. G. (1982) Urinary enzymes, nephrotoxicity and renal disease. Toxicology 23, 99-134.

3. Burchardt, U., Schinköthe, G., Müller, G., Neef, L. \& Krötsch, H. (1978) Ausscheidungskinetik von Enzymen und Protein mit dem Harn bei Applikation therapeutischer Gentamycindosen. Schweiz. Med. Wochenschr. 108, $1541-$ 1545.

4. Feldmann, D., Flandrois, C., Jardel, A., Phan, T.-M. \& Aymard, P. (1989) Circadian variations and reference intervals for some enzymes in urine of healthy children. Clin. Chem. 35, 864-867.

5. Maruhn, D., Strozyk, K., Gielow, L. \& Bock, K. D. (1977) Diurnal variations of urinary enzyme excretion. Clin. Chim. Acta 75, 427-433.

6. Grötsch, H., Hropot, M., Klaus, E., Malerczyk, V. \& Mattenheimer, H. (1985) Enzymuria of the rat: biorythms and sex differences. J. Clin. Chem. Clin. Biochem. 23, 343347.

7. Burchardt, U., Winkler, K., Klagge, M., Balschun, D. \& Barth, A. (1988) Infradian biorhythms of enzymuria in man? J. Clin. Chem. Clin. Biochem. 26, 491-496.

8. Press, W. H., Fiannery, B. P., Teukolsky, S. A. \& Vetterling, W. T. (1988) Numerical recipes; The art of scientific computing. Cambridge.
The membrane damage produced by aminoglycosides is counteracted by repair processes. In this context an amplification of circaseptan periods in enzyme excretion as described here seems to be plausible. The circaseptan rhythms are thought to be connected with reactive and adaptive phases of the organism (14). Devecchi et al. (15) reported circaseptan periods in the rejection of kidney transplants. Thus, the importance of circaseptan rhythms in physiology and their clinical application should be pursued in further investigations.

\section{Acknowledgement}

We thank Dr. $U$. Schmidt, Institute of Biomathematics and Medical Informatics, Magdeburg, for his support.

9. Kay, S. M. (1987) Modern spectral estimation; Theory \& application. Englewood Cliffs.

10. Kamath, M. V., Reddy, S. N., Ghista, D. N. \& Upton, A. R. M. (1987) Power spectral analysis of normal and pathological brainstem auditory evoked potentials. Int. J. BioMedical Computing 21, 33-54.

11. Grötsch, H., Hropot, M., Klaus, E. \& Wesely, J. (1990) Influence of seasonal biorhythms on urinary excretion of enzymes and other parameters. J. Clin. Chem. Clin. Biochem. 28, 285-286.

12. Gilbert, D. N., Houghton, D. C., Bennett, W. M., Plamp, C. E., Reger, K. \& Porter, G. A. (1979) Reversibility of gentamicin nephrotoxicity in rats: recovery during continuous drug administration. Proc. Soc. Exp. Biol. Med. 160, 99-103.

13. Severini, G. \& Aliberti, L. M. (1987) Variation of urinary enzymes $\mathrm{N}$-acetyl-beta-glucosaminidase, alanine-aminopeptidase, and lysozyme in patients receiving radiocontrast agents. Clin. Biochem. 20, 339-341.

14. Hildebrandt, G. \& Geyer, F. (1984) Adaptive significance of circaseptan reactive periods. J. Interdiscipl. Cycle Res. 15, 109-117.

15. Devecchi, A., Halberg, F., Sothern, R. B., Cantaluppi, A. \& Ponticelli, C. (1981) Circaseptan rhythmic aspects of rejection in treated patients with kidney transplants. In: Chronopharmacology and Chronotherapeutics. (Walker, C. A., Winget, C. M. \& Soliman, K. F. A., eds.) Tallahassee, pp. $339-353$.

Dr. Detlef Balschun
Institute of Neurobiology
and Brain Research
Brenneckestraße 6
O-3090 Magdeburg
Germany

